\title{
Histological findings of testicular biopsy in North Indian population
}

\author{
Arpita Mahajan*, Smita Kakar, J. M. Kaul, Sabita Mishra
}

Department of Anatomy, Maulana Azad Medical College, Delhi University, New Delhi-110002, India

Received: 09 February 2015

Revised: 17 February 2015

Accepted: 01 March 2015

\author{
*Correspondence: \\ Dr. Arpita Mahajan, \\ E-mail: arpitamahajan27@gmail.com
}

Copyright: $($ the author(s), publisher and licensee Medip Academy. This is an open-access article distributed under the terms of the Creative Commons Attribution Non-Commercial License, which permits unrestricted non-commercial use, distribution, and reproduction in any medium, provided the original work is properly cited.

\begin{abstract}
Background: Infertility is defined as the inability to achieve pregnancy after one year of unprotected intercourse. To interpret these testicular causes, biopsy of testis and its classification becomes an important tool for diagnoses. Biopsy is mostly done in severe oligozoospermic or azoospermic patients. Biopsies are also important in recent times due to introduction of Assisted Reproductive Techniques (ART) because they determine the level of spermatogenesis. In the present study the testicular biopsy has been classified into seven categories. One of the classification is that of the highly homogenous mass, which is an addition to the studies done previously. The increase in connective tissue has been demonstrated by Masson's trichrome stain not cited in the literature. This study will help relook into the way of categorising the testicular biopsy which will benefit those seeking treatment of male infertility.

Methods: The study was carried out on 30 infertile patients who were either azoospermic (nil to $<2 \times 10^{6} \mathrm{sperms} / \mathrm{ml}$ ) or severe oligozoospermic $\left(<5 \times 10^{6}\right.$ sperms $\left./ \mathrm{ml}\right)$. Testicular biopsy of these patients was taken after obtaining ethical clearance and written consent of the patients. The biopsy was processed, stained and assessed using haematoxylin and eosin and Masson's trichrome. They were classified into different histological types. They were also categorised by modified Johnsen scoring.

Results: The biopsies were classified histologically into obstructive azoospermia in 4 cases (13.33\%). Hypospermatogenesis in 5 cases (16.66\%), maturation arrest in 3 cases (10\%), sertoli cell only syndrome in 3 cases $(10 \%)$, seminiferous tubule hyalinization in 7 cases $(23.33 \%)$, mixed patterns in 6 cases $(20 \%)$ and highly cellular homogenous tissue in 2 cases $(6.66 \%)$. The last condition has not been classified in the literature cited.

Conclusions: By the present study we can determine the level of spermatogenesis and by studying the nature of different germ cells we can use it for ART. Consideration of the biopsy being taken from a particular part of the testis must be kept in mind, and there might be the possibility of spermatogenesis occurring in some other quadrant. The patient needs to be explained this.
\end{abstract}

Keywords: Testicular biopsy, Male infertility, Histological classification

\section{INTRODUCTION}

The investigation of male infertility includes history, physical examination, biochemical investigations, semen analysis and testicular biopsy. ${ }^{1}$ The first investigation as an infertile patient approaches for treatment is semen analysis. Some patients with low semen count need to get a testicular biopsy done. The combination of testicular biopsy and clinical evaluation for male infertility is becoming progressively more important because new technologies allow men previously considered infertile to father a child. ${ }^{2}$

Earlier studies have categorized biopsies into different conditions. In men with azoospermia (sperm count nil), testicular biopsy determines if a blockage is present in the sperm pathway as there is presence of germ cells on histological examination of the testicular tissue. If there is primary testicular failure no germ cells are seen in the biopsy. ${ }^{3}$ For obstructive azoospermic patients with 
normal spermatogenesis, biopsy can be used to identify spermatozoa or spermatids, which can be therapeutically used in assisted reproductive techniques. ${ }^{4-6}$

To understand testicular biopsy, knowledge of spermatogenesis and detailed information about the organization of the germinal epithelium its structure and function of different types of germ cells is necessary. Normally all stages of differentiation are not present simultaneously and hence normal spermatogenesis does not yield mature spermatids in every tubular cross section in a testicular biopsy. Various immature stages are normally observed and do not necessarily mean a maturation abnormality. Histologically each tubule has a basement membrane composed of a basal lamina and laminated connective tissue containing numerous fibres covered externally by flat epitheloid cells. Internal to it, the seminiferous epithelium consists of spermatogenic and supportive cells. The former when active include an array of types ranging from spermatogonia through their derived forms, spermatocytes and spermatids to mature spermatozoa. In the fully differentiated testis they appear along the basal laminae of the seminiferous tubules. ${ }^{5,6}$ Primary spermatocytes at first resemble in size and cytological characteristics the spermatogonia from which they arise but as they move away from basal lamina of the germinal epithelium, they accumulate more cytoplasm and become distinctly larger. After completion of meiosis I there is formation of secondary spermatocytes carrying only half the number of chromosomes originally present. The secondary spermatocytes quickly complete the second phase of meiotic division and spermatids are formed that have a haploid set of chromosomes. ${ }^{7}$ Sertoli cells or sustentacular cells abut on the basal lamina of the tubules. In tangential sections, these are polygonal and in transverse section the same are columnar. ${ }^{5,8,9}$ Leydig cells lie in the interstitial tissue in small and sometimes large groups. The intertubular tissue contains fibroblasts, collagen and blood vessels. ${ }^{10,11}$

Spermatogenesis is the series of changes by which spermatogonia are transformed into spermatozoa. It may be divided into three phases, spermatocytogenesis, in which spermatogonia proliferate by mitotic division to produce primary spermatocytes. In the second phase (meiosis) successive maturation divisions produce secondary spermatocytes and spermatids, all with haploid number of chromosomes. The third phase is spermiogenesis when the spermatids become spermatozoa. ${ }^{5,12,13}$

The spermatogenic cycle is defined as a series of changes in a given region of seminiferous epithelium between two appearances of the same developmental stages. Using spermiation as reference, the cycle is composed of all the events that occur in a given region of the tubule between two consecutive spermiations. In humans the 27 days of spematocytogenesis, 24 days of meiosis, and 23 days of spermiogenesis compose the 74-day duration of spermatogenesis. ${ }^{10,14}$

The biopsies studied by various scientists have been categorized into different conditions and each of these needs to be dealt clinically at an individual level. The present study highlights the various conditions in the north Indian population.

\section{METHODS}

The study was carried out on 30 patients who had presented to Surgery OPD with complaint of infertility. Semen analysis was carried out to categorize them, cases of azoospermia or severe oligozoospermia were taken as subjects for study. Testicular biopsy of these patients were taken in department of surgery after obtaining ethical clearance and written consent. The biopsy was processed, stained and assessed.

\section{Collection and processing of biopsy}

The testicular biopsy of one side was obtained by removal of a small piece of tissue while the patient was under light anesthesia (conscious sedation) and tissue was preserved in $10 \%$ buffered formalin for 1 week. Tissue was labeled and embedded in paraffin and sections were cut at $5 \mu$ with rotary microtome. The testicular morphology was analyzed after staining with haematoxylin \& eosin and Masson's trichrome. Testicular tissue was also obtained from fresh male cadavers in department of anatomy and the one that showed normal spermatogenesis was used as a control for the study. The testicular biopsies were first analyzed qualitatively under low power and study of cells was done at high power.

The control showed seminiferous tubules which had germ cells and sertoli cells confined to the basement membrane. Spermatogonia were close to the basement membrane and had clumped nuclear chromatin. Primary spermatocytes were largest cells, displaying a scattered chromatin and secondary spermatocytes formed an inner layer of smaller cells. Spermatids were 2 to 3 layers of small round cells with oval nuclei and late spermatids were more flattened. Sertoli cells were pyramidal in shape and stood at intervals on basement membrane. Leydig cells occurred in intertubular tissue, were large and polyhedral, with an eccentric nucleus and a scanty and poorly stained cytoplasm. Leydig cells, connective tissue and blood vessels were in the interstitial tissue. Myoid cells with flattened nuclei were just external to the basement membrane.

\section{RESULTS}

The thirty testicular biopsies obtained from Department of surgery were studied after processing and staining, a normal testis was used as control (Figure 1) to compare. The morphology of biopsied tissues studied 
qualitatively/with respect to the tubules, basement membrane and interstitium. The haematoxylin and eosin staining was used to identify the germ cells, leydig cells and interstitial tissue. To study the increased connective tissue Masson's trichrome staining was used. On the basis of above description the biopsies were classified histologically into seven types in Table 1.

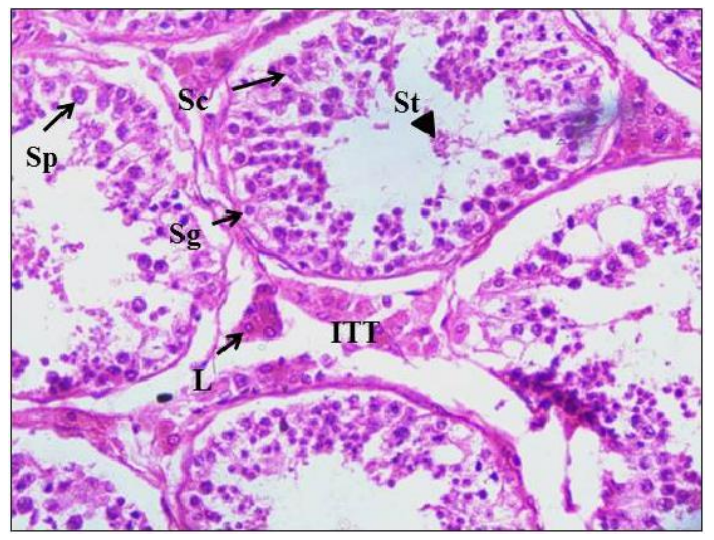

Figure 1: Normal testis: Haematoxylin and Eosin (H\&E) staining in normal testis at 40x (magnification) showing seminiferous tubules with normal spermatogenesis, intertubular connective tissue (ITT), spermatogonia $(\mathrm{Sg})$, spermatocyte $(\mathrm{Sp})$, sertoli cell $(\mathrm{Sc})$, spermatids $(\mathrm{St})$, leydig cells $(\mathrm{L})$.

Table 1: Histopathological classification of male infertility.

\begin{tabular}{|lll|}
\hline Clinical condition & $\begin{array}{c}\text { No. of } \\
\text { cases }\end{array}$ & $\%$ \\
\hline Obstructive azoospermia & 4 & $13.33 \%$ \\
\hline Hypospermatogenesis & 5 & $16.66 \%$ \\
\hline Maturation arrest & 3 & $10 \%$ \\
\hline Sertoli cell only syndrome & 3 & $10 \%$ \\
\hline Seminiferous tubule hyalinization & 7 & $23.33 \%$ \\
\hline Mixed pattern & 6 & $20 \%$ \\
\hline Highly homogenous mass & 2 & $6.66 \%$ \\
\hline
\end{tabular}

Obstructive azoospermia (Figure 2a, 2b) showed essentially normal spermatogenesis with a high density of germ cells in the tubules, azoospermia on semen analysis implied obstruction of some part of the duct system. In Hypospermatogenesis (Figure 3), tissue showed a decrease in the total number of germ cell types though all stages of the spermatogenesis were seen, the sperm count was severe oligozoospermic or azoospermic. Maturation Arrest (Figure 4) presented the germ cells upto the spermatocytic stage, the semen mostly showed azoospermia. Sertoli cell only syndrome (Figure 5) had only sertoli cells with no or very few germ cells in the seminiferous tubules, the semen analysis mostly showed azoospermia. Seminiferous tubule hyalinization (Figure 6a, 6b, 6c, 6d) showed no tubules but increased connective tissue with azoospermia. In Mixed patterns hypospermatogenesis with maturation arrest was seen commonly in our study (Figure 7a, 7b). Two of the biopsies showed haphazardly scattered cells which could not be defined, no tubules were seen.

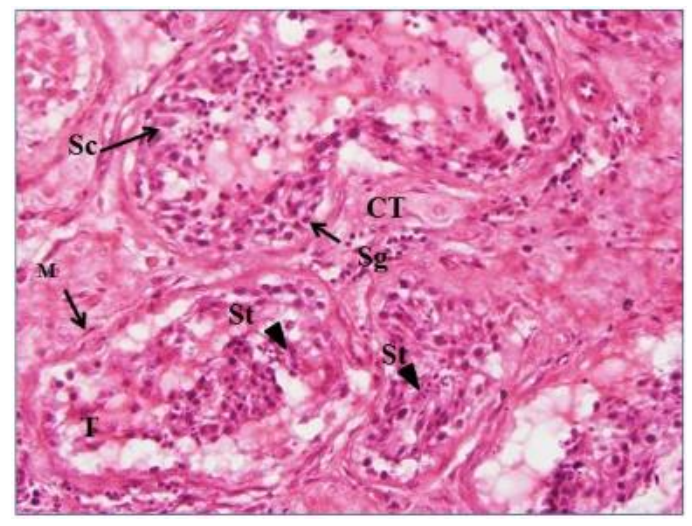

Figure 2a: Obstructive azoospermia: H\&E staining in obstructive azoospermia at $40 x$. Increased connective tissue (CT), spermatogonia (Sg), sertoli cell (Sc), spermatids (St) and myoid cell $(\mathrm{M})$.

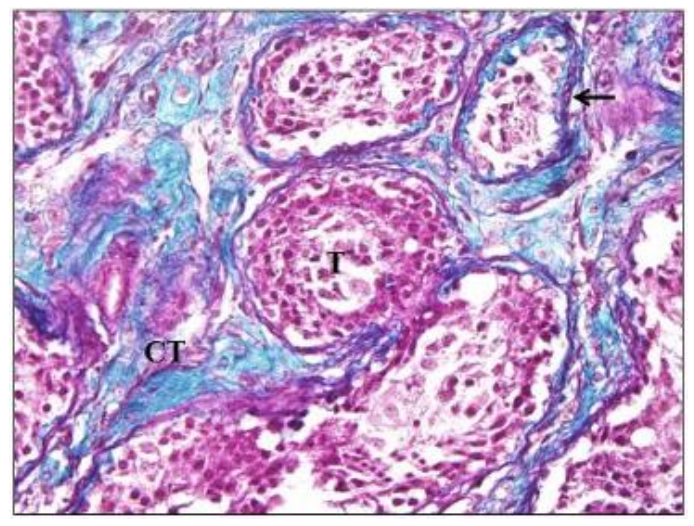

Figure 2b: Obstructive azoospermia: Masson's trichrome staining in obstructive azoospermia at 40x showing connective tissue (CT). Seminiferous tubules (T) seen. Basement membrane shown with the arrow.

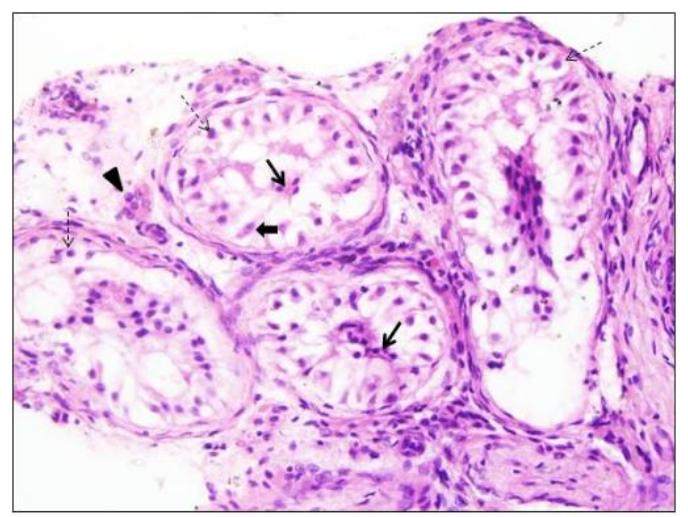

Figure 3: Hypospermatogenesis: H\&E staining in hypospermatogenesis at 40x. Stippled arrow showing spermatogonia, small bold arrow showing spermatids, big bold arrow showing sertoli cell. Arrow head showing leydig cells. 


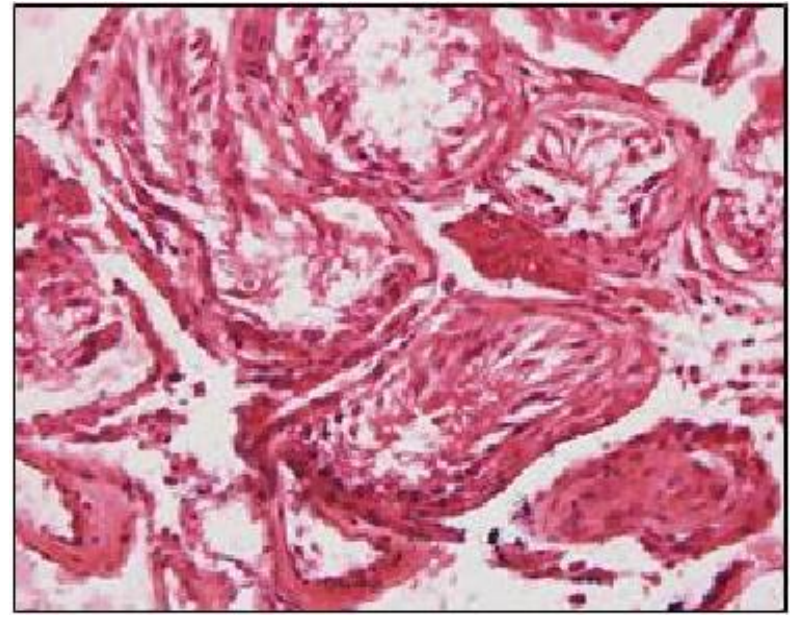

Figure 4: Maturation arrest: H\&E staining in maturation arrest at 40x. Stippled arrows showing spermatogonia and big bold arrow showing sertoli cell showing sertoli cell. Bold arrow heads showing leydig cells.

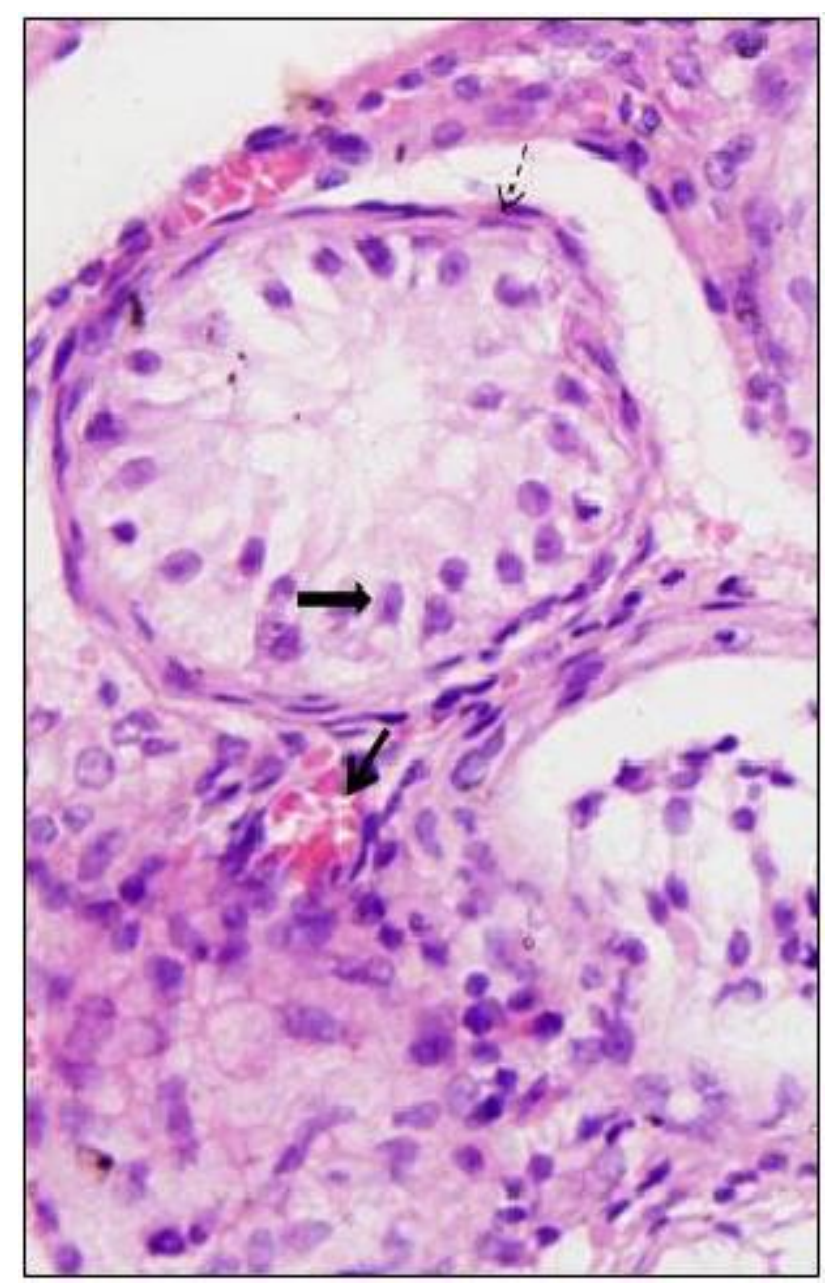

Figure 5: Sertoli cell only syndrome: H\&E staining in sertoli cell only syndrome at 40x. Big bold arrow showing sertoli cell, stippled arrow showing myoid cells and bold arrow showing blood vessel.

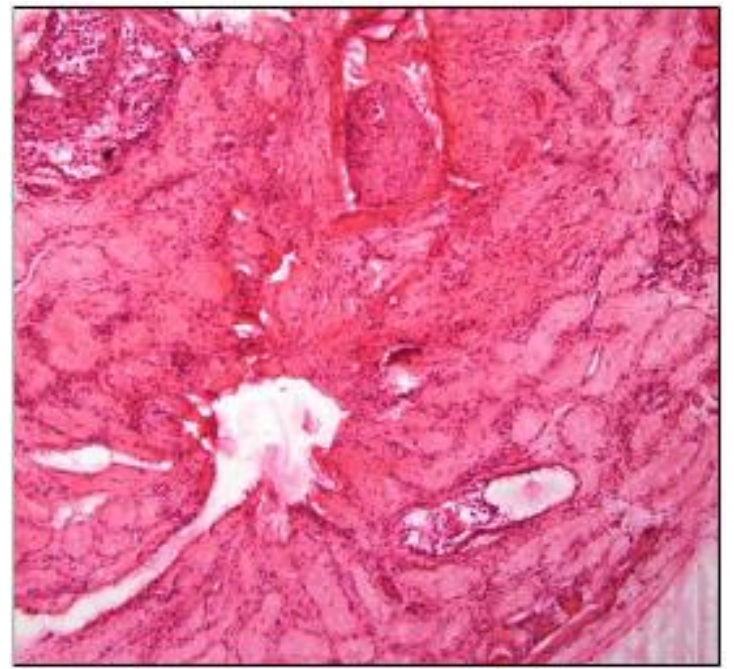

Figure 6a: Seminiferous tubule hyalinization: H\&E staining in seminiferous tubule hyalinization at 10x. The tubular outline cannot be seen.

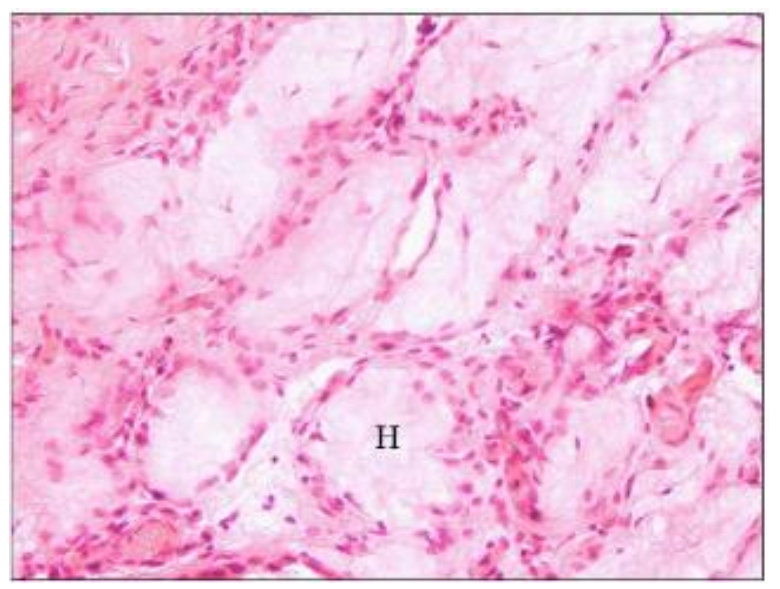

Figure 6b: Seminiferous tubule hyalinization: H\&E staining in seminiferous tubule hyalinizationat $40 x$. Hyalinization (H) seen.

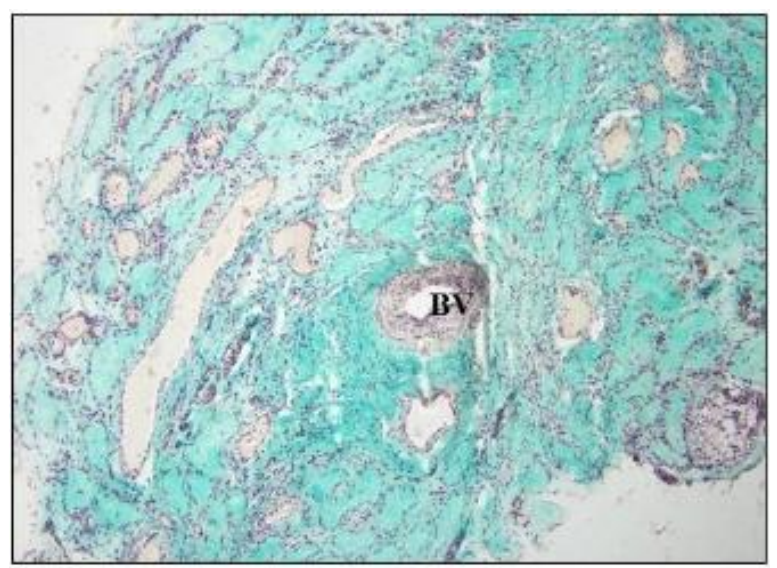

Figure 6c: Seminiferous tubule hyalinization: Masson's trichrome staining in seminiferous tubule hyalinization at 10x. Hyalinization seen. Blood vessel (BV) seen. 


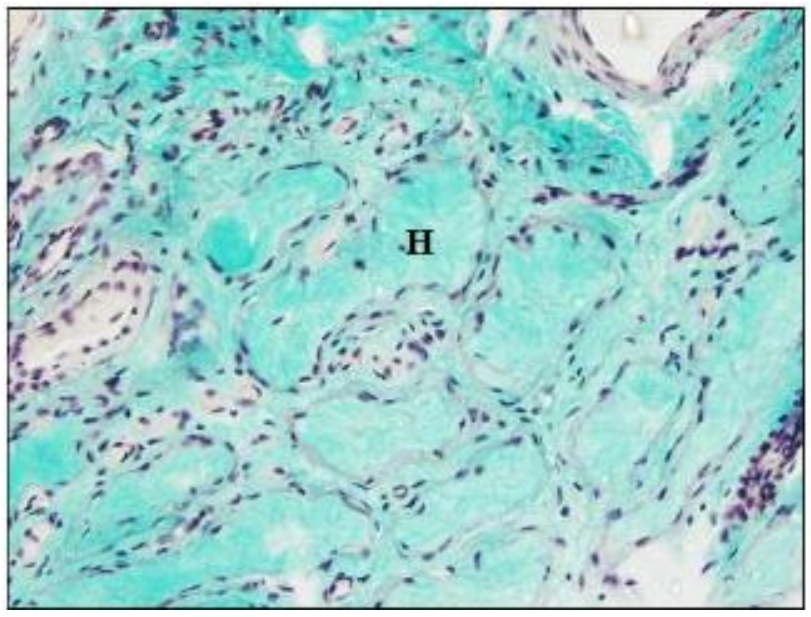

Figure 6d: Seminiferous tubule hyalinization: Masson's trichrome staining in seminiferous tubule hyalinization at 40x. Hyalinization $(H)$ seen.

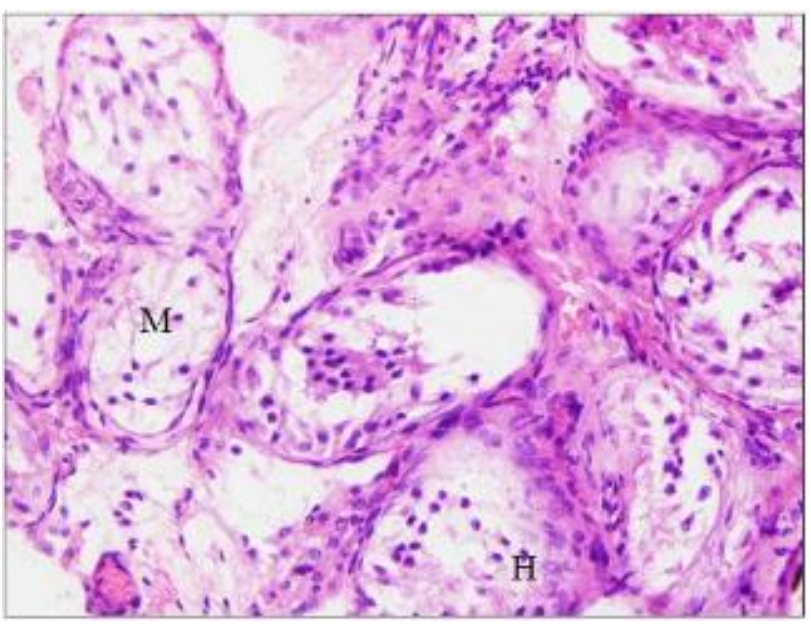

Figure 7a: Mixed patterns: H\&E staining in mixed pattern at 40x. Hypospermatogenesis shown by $(\mathrm{H})$ and maturation arrest by $(M)$.

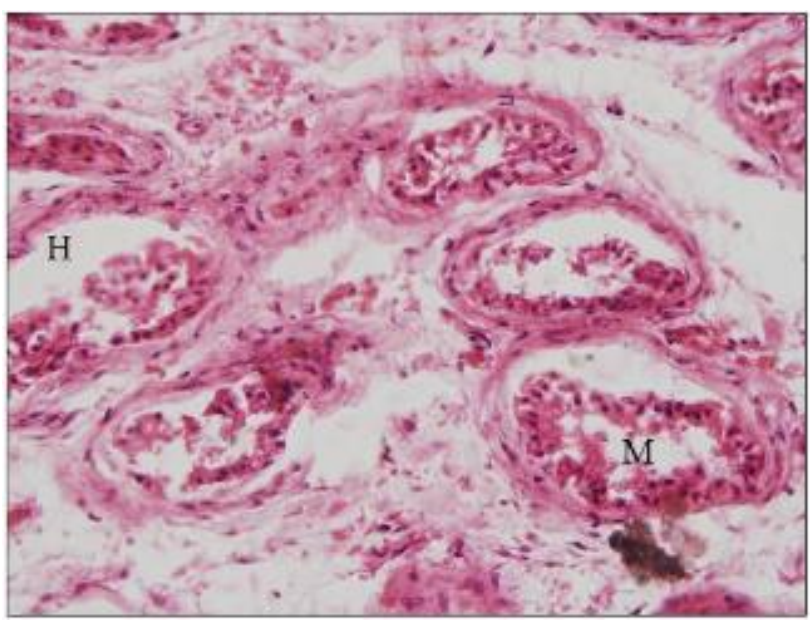

Figure 7b: Mixed patterns: H\&E staining in mixed pattern at 40x. Hypospermatogenesis shown by $(\mathrm{H})$ and maturation arrest by $(M)$.

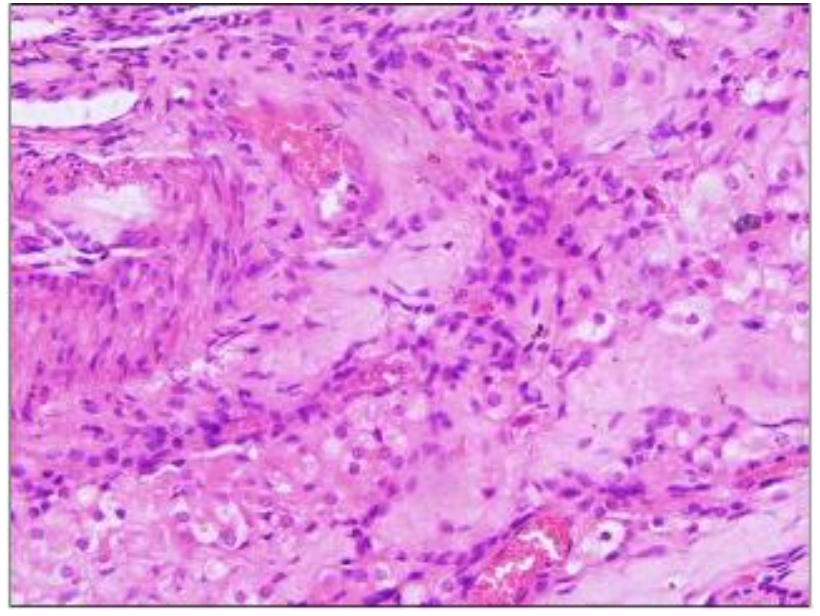

Figure 8a: Highly cellular homogenous mass: H\&E staining in highly cellular homogenous mass at $40 x$.

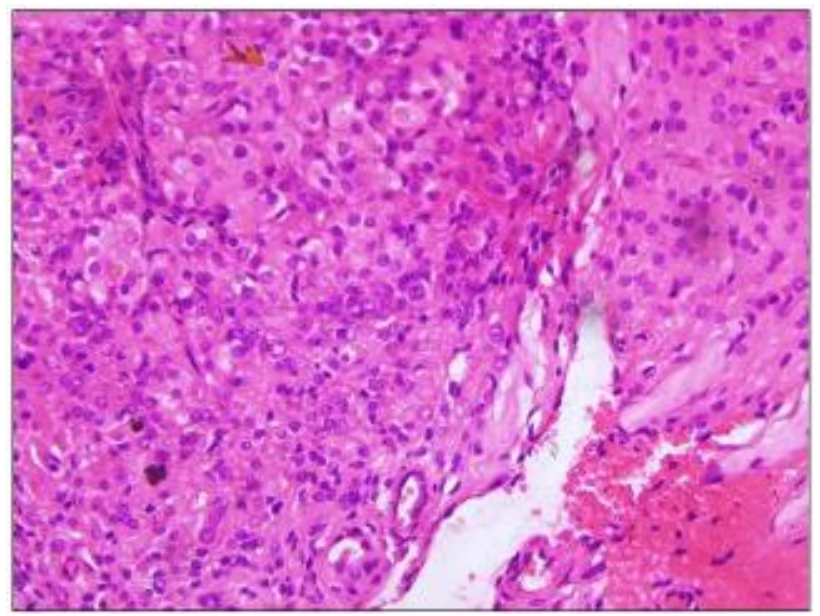

Figure 8b: Highly cellular homogenous mass: H\&E staining in highly cellular homogenous mass at $40 x$.

\section{DISCUSSION}

Testicular biopsy is an important tool in the investigation and the assessment of male infertility. It may shed some light on the etiology as well as providing essential prognostic information. The histological patterns in the testicular biopsies are classified according to the presence and amount of spermatogenesis, maturation of germinal cells and presence of associated tubular atrophy, interstitial fibrosis. It is not the only parameter for determining the testicular histopathology pattern but apparently the strongest indicator to foresee the possibility of finding sperms in the testis for therapeutic sperm retrieval in assisted reproductive techniques. The introduction of intracytoplasmic sperm injection revolutionized the treatment of male infertility by requiring a minimal number of sperm to achieve pregnancy. The surgical testicular biopsy techniques followed by morphologic examination, permits many patients with infertility to receive a favorable prognosis and therapeutic trial. ${ }^{6}$ In addition, testicular biopsy is important in the evaluation of men at risk for testicular 
cancer. $^{2}$ The testicular biopsy for infertility requires understanding of a different set of diagnostic categories not otherwise commonly encountered. ${ }^{3}$

Studying human spermatogenesis will benefit clinicians, toxicologists, and epidemiologists by direct evaluation of testis or indirectly via evaluations of quantity and quality of sperm ejaculated. It also will benefit scientists interested in renewal and proliferation of spermatogonia as a prototype stem cell. ${ }^{14}$

Since classification of biopsies is important to determine treatment of the infertile patient they were categorised into obstructive azoospermia with normal spermatogenesis, hypospermatogenesis, maturation arrest, sertoli cell only syndrome (Germinal cell aplasia), seminiferous tubular hyalinization, mixed pattern and highly cellular homogenous mass. The above classification, has been used by many authors in their studies, ${ }^{4,15}$ There are a few authors who have added a mixed pattern, showing more than one type of pattern in a particular biopsy. ${ }^{2,19,20}$ The homogenous mass has not been described in any of the studies cited. In our study tubular hyalinization was the most common cause of male infertility followed by hypospermatogenesis, which is the most common cause according to some studies. ${ }^{1} \mathrm{~A}$ comparison has been worked out with the work of other authors and has been described in Table 2 .

To describe each of the above conditions the biopsies were studied systematically according to previous studies. Obsrtructive azoospermia was reported when the tubules showed all stages of spermatogenesis but with increase in number as compared to a normal control. Cases of maturation arrest were classified by evaluating whether spermatogenesis proceeds to full spermatid differentiation across the tubules. It was done by working backwards for the presence of elongated spermatids across tubules, if they were absent, then working backward through spermatocytes to spermatogonia allowed us to note at which level differentiation was arrested. Germ cell arrest was diagnosed only if there was no maturation beyond an immature stage in all tubules present within the biopsy. When there was heterogeneous i.e. some tubules showed a particular condition and others showed another pattern a mixed pattern was reported. The term sertoli-cell-only syndrome was reserved for those cases in which all the tubules in the biopsy showed absence of germ cells with presence of sertoli cells. If the tubular basement membranes were thickened, along with absence of germ cell development and shrunken lumens, the diagnosis was tubular hyalinization. We saw a few cases which showed haphazard arrangement of cells which could not be classified into above groups and were put under highly homogenous tissue. A comparison of our study with the other authors has been done in table II. The distinction between obstructive and non-obstructive azoospermia is important. Testicular biopsy helps to differentiate between them. Men with obstructive azoospermia may have options for treatment, such as surgical reconstruction of the reproductive tract.

Table 2: Comparison of the present study with other studies.

\begin{tabular}{|llllll|}
\hline Condition & $\begin{array}{l}\text { Abdullah L } \\
\text { et al. }\end{array}$ & $\begin{array}{l}\text { Wong TW } \\
\text { et al. }\end{array}$ & $\begin{array}{l}\text { Rosai J } \\
\text { et al. }\end{array}$ & $\begin{array}{l}\text { Brannen GE } \\
\text { et al. }\end{array}$ & $\begin{array}{l}\text { Present } \\
\text { study }\end{array}$ \\
\hline Obstructive azoospermia & $13 \%$ & - & $27 \%$ & - & $13.33 \%$ \\
\hline Hypospermatogenesis & $29 \%$ & $22.9 \%$ & - & $23 \%$ & $16.66 \%$ \\
\hline Maturation arrest & $12 \%$ & $32.1 \%$ & $26 \%$ & $4 \%$ & $10 \%$ \\
\hline Sertoli-cell-only syndrome & $16 \%$ & - & $29 \%$ & $12.5 \%$ & $10 \%$ \\
\hline Seminiferous tubular hyalinization & $16 \%$ & & $18 \%$ & $12.5 \%$ & $23.3 \%$ \\
\hline Mixed patterns & $9 \%$ & - & - & - & $20 \%$ \\
\hline Highly cellular homogenous mass & - & - & - & - & $6.66 \%$ \\
\hline
\end{tabular}

Non-obstructive azoospermia may be caused by many causes but most are idiopathic. Testicular biopsy may show scattered foci of spermatogenesis in some cases with potential for surgical sperm retrieval and intracytoplasmic sperm injection but a real risk of failure to retrieve spermatozoa exists in men with nonobstructive azoospermia and couples must be informed of this risk before attempting assisted reproduction as the area from where the biopsy is obtained may or may not be having spermatogenesis. Men with non-obstructive azoospermia should have genetic testing as $15-30 \%$ of them have sex chromosome aneuploidy or $\mathrm{Y}$ chromosome deletions. ${ }^{20-22}$
On starting the TESE-ICSI programme a preliminary explorative testicular biopsy is done to ascertain that complete spermatogenesis is present in at least some seminiferous tubules in order to guarantee sperm retrieval for the planned TESE-ICSI attempt. If the sperms are not available some studies suggest use of spermatids which is under study. $^{23}$ Male infertility study requires systematization of clinical and paraclinical diagnostic procedures and the knowledge of techniques to analyze functional capacity of human spermatozoon. The application of the various methods of assisted reproduction in male infertility treatment, should be judged with a good criterion in order to offer maximal benefit and least risk. The present study will help in 
determining the nature of germ cells in the testicular biopsy which will benefit in above procedures.

Consideration of the biopsy being taken from a particular part of the testis must be kept in mind, and there might be the possibility of spermatogenesis occurring in some other quadrant. The patient needs to be explained this. Patients in whom ICSI is not possible, need to go for surrogacy or adoption.

Funding: No funding sources Conflict of interest: None declared

Ethical approval: The study was approved by the institutional ethics committee

\section{REFERENCES}

1. Shefi S, Turek PJ. Definition and current evaluation of subfertile men. Int Braz J Urol. 2006 Jul;32(4):385-97.

2. Abdullah L, Bondagji N. Histopathological patterns of testicular biopsy in male infertility: a retrospective study from a tertiary care centre in the western part of Saudi Arabia. Urol Ann. 2011 Jan-Apr;3(1):19-23.

3. Brugh VM, Lipshultz LI. Male factor infertility: Evaluation and management. Med Clin North Am. 2004 Mar;88(2):367-85.

4. Wong TW, Strauss FH, Warner NE. Testicular biopsy in the study of male infertility. Arch Pathol. 1973;95:151-9.

5. Williams PL, Bannister LH, Berry MM, Collins P, Dyson M, Dussek JE. Reproductive organs of the male. In: Williams PL, Bannister LH, Berry MM, Collins P, Dyson M, Dussek JE, eds. Gray's Anatomy, 38th ed. London: Elsevier Churchill Livingstone; 2000: 1849-1851.

6. Ross MH, Pawlina W. Male reproductive system: spermatogenesis. In: Ross MH, Pawlina W, eds. Histology. A Text and Atlas. 6th ed. Philadelphia: Lippincott Williams \& Wilkins; 2011: 793.

7. Bloom W, Fawcett DW. Male reproductive system. In: Bloom W, Fawcett DW, eds. A Textbook of Histology. 11th ed. Philadelphia: W.B. Saunders; 1986: 796-850.

8. Ronald CS. The testis: the normal testis. Arch Pathol. 1950 Sep;50(3):260-84.

9. Kobil E, Neill JD. Cytology of testis and intrinsic control mechanisms. In: Kobil E, Neill JD, eds. Physiology of Reproduction, 3rd ed. US: Elsevier; 2006: 865-886.

10. Wallace RL. Testis overview. In: Wallace RL, eds. Encyclopedia of Reproduction. 4th ed. US: Academic Press; 1998: 778-783.
11. Kerr JB. Functional cytology of the human testis. Baillieres Clin Endocrinol Metab. 1992 Apr;6(2):235-50.

12. Johnson L. Efficiency of spermatogenesis. Microsc Res Tech. 1995 Dec;32(5):385-422.

13. Miething A. The establishment of spermatogenesis in the seminiferous epithelium of the pubertal golden hamster (Mesocricetus auratus). Adv Anat Embryol Cell Biol. 1998;140:43-64.

14. Clermont Y. Dynamics of human spermatogenesis. In: Clermont Y, eds. Proceedings of the Workshop Conference on the Human Testis in Positano. Italy: Plenum Press; 1970: 47-57.

15. Rosai J. Male reproductive system: normal embryology and anatomy. In: Rosai J, eds. Surgical Pathology. 9th ed. US: Elsevier; 2004: 1412-1413.

16. Brannen GE, Roth RR. Testicular abnormalities of the subfertile male. J Urol. 1979 Dec;122:757-62.

17. Anthony S, Leong Y, Mathews CD. The role of testicular biopsy in the investigation of male infertility. Pathology. 1982 Apr;14(2):205-10.

18. Ronald CS, Howard RP, Simmons FA. The Testis: abnormalities of spermatogenesis. Arch Pathol. 1950 Sep;50(3):285-95.

19. Mills SE. Urinary tract and male genital system. In: Mills SE, eds. Diagnostic Surgical Pathology. 4th ed. Philadelphia: Lippincott Williams \& Wilkins; 2004: 2142-2150.

20. Cerilli LA, Kuang W, Rogers D. A practical approach to testicular biopsy interpretation for male infertility. Arch Pathol Lab Med. 2010 Aug;134:1197-204.

21. Hung AJ, King P, Schlegel PN. Uniform testicular maturation arrest: a unique subset of men with nonobstructive azoospermia. J Urol. 2007 Aug;178(2):608-12.

22. Maymon BB, Yogev L, Paz G, Kleiman SE, Schreiber L, Botchan A, et al. Sertoli cell maturation in men with azoospermia of different etiologies. Fertil Steril. 2002 May;77(5):904-9.

23. Vanderzwalmen $\mathrm{P}$, Zech $\mathrm{H}$, Birkenfeld A, Yemini M, Bertin G, Lejeune B, et al. Intracytoplasmic injection of spermatids retrieved from testicular tissue: influence of testicular pathology, type of selected spermatids and oocyte activation. Hum Reprod. 1997;12(6):1203-13.

DOI: $10.5455 / 2320-1770 . i j r c o g 20150429$

Cite this article as: Mahajan A, Kakar S, Kaul JM, Mishra S. Histological findings of testicular biopsy in North Indian population. Int J Reprod Contracept

Obstet Gynecol 2015;4:432-8. 